\title{
1526: A FUNDACIÓN DA UNIVERSIDADE DE SANTIAGO
}

\author{
Por \\ ANTÓN COSTA RICO
}

\section{¿TEN 500 ANOS A UNIVERSIDADE DE SANTIAGO?}

Durante o curso académico de 1995-96 a Universidade de Santiago conmemorou o seu V Aniversario (1495-1995). As oportunas decisión dos órganos de goberno universitario, por invitación sucesiva dos Rectores D. Ramón Villares e D. Darío Villanueva, permitiron levar a cabo un denso programa de actividades e iniciativas culturais e académicas (Encontros, Congresos, Exposicións, Publicacións...), conducentes a recoñecer o pasado universitario, a reflexionar sobre o noso presente e a proxectar valiosas orientacións de futuro, como tamén a fortalecer as relacións entre a institución universitaria e a sociedade e a insertar a universidade no marco internacional da sociedade do coñecemento.

A conmemoración deulle unha particular tonalidade á vida universitaria e compostelana, quedando o curso de 1995-96 na retina e na memoria de todos os que tivemos, dun modo ou de outro, a oportunidade de vivir ese momento singular, porque, é do caso salientar que o programa conmemorativo foi amplo e mesmo intenso e interesante, por máis que rexistrase algunhas carencias.

Pero, como consecuencia dalgunhas das orientacións dadas á esta conmemoración, puido quedar unha mensaxe non estrictamente certa relativa aos 500 anos da Universidade de Santiago; ao caso, resulta evidente a xeneralización dunha información historiograficamente non obxectiva e

"CUADERNOS DE eSTUdiOS GALLEGOS", Tomo XLVI, Fascículo 111, Santiago 1999. 
históricamente defectuosa ao respecto. Información alimentada a través de múltiples intervencións e comunicacións dos medios de información e mesmo, nalgunha medida, asentada en aseveracións de historiadores universitarios, que non respostan con exactitude ao actual estado da cuestión referido aos estudios históricos universitarios.

Debe sinalarse que os máis prestixiosos estudios de investigación histórica universitaria en Europa non acollen en ningún caso a fundación da universidade de Santiago con anterioridade ao ano 1500, reservando case todos eles a data de 1526 e as figuras de Alonso III de Fonseca e do Papa Clemente VII, como os artifices da súa fundación, se ben tales estudios recoñezan a existencia duns antecedentes próximos a partir de 1495 e mellor a partir da Bula Papal do 1504. A este respecto, parece oportuno indicar que tales estudios e as clasificacións cronolóxicas do nacemento das Universidades en Europa, recoñecidas con criterio de autoridade académica, non teñen sido manifestamente incorporados ao aparato crítico utilizado polo conxunto da historiografía universitaria galega ata o momento.

Así pois, pasados os momentos de Conmemoración, cremos non ser inoportuno abordar a cuestión do punto de partida e da fundación certa da Universidade Compostelana, que hai que situar, sen dúbida, no 1526 e non antes, anque iso quizais non faga ilícito ter realizado a conmemoración a partir dos antecedentes, pesando na decisión considerables razóns extraacademicas.

Estrictamente falando, desde o respeto crítico ao saber científico de caracter histórico, a Universidade de Santiago non ten aínda 500 anos. A conmemoración estricta do V Centenario correspóndelle ao futuro 2026. ¿Como será daquela a Universidade de Santiago?; ¿estará presidida, por exemplo, por unha das primeiras Rectoras dunha institución centenaria?.

Inquedados os lectores pola veracidade das anteriores aseveracións, debemos, sen máis dilación, abordar o asunto. 


\section{ANTECEDENTES, ORIXE E FUNDACIÓN DA UNIVERSIDADE DE SANTIAGO: DADOS E DOCUMENTOS}

Desde mediados do século XI hai constancia da existencia dunha Escola de Gramática na Catedral de Santiago ${ }^{1}$, que posibilitaba unha formación literaria básica á clerecia compostelana, propedéutica para a formación posterior que algúns daqueles clerigos acadaron durante os séculos XII e XIII nas Universidades de París e de Bolonia.

No inicio do seculo XIII, formando parte Galicia do chamado Reino de León, gobernado daquela por un rei de ascendencia galega, que non por casualidade está soterrado no Panteón Real de Santiago, Alfonso IX, este foi o creador da Universidade de Salamanca, nunha data imprecisa entre 1218-1219, a partir da Escola de Gramática catedralicia de tal cidade. A diocese salmantina pertencía ao arcebispado de Santiago, sendo galegos naqueles momentos o seu bispo e varios dos membros do seu Cabido ${ }^{2}$. A este respecto, o recoñecido historiador Beltrán de Heredia ${ }^{3}$ resalta a importancia extrema da Escola de Gramática compostelana en canto que modelo e formadora de parte notable do primeiro profesorado universitario salmantino, de orixe galego, con validez do aserto para o conxunto do século XIII.

Como reflexo desta conexión galego-salmantina, poderase destacar que durante o primeiro tercio do século XIV, os arcebispos de Compostela, D. Rodrígo de Padrón (1307-1316) e D. Berenguel de Landoria (1317-1330), como metropolitanos, velarán pola seguridade da vida institucional da universidade de Salamanca, comportándose -como ten afirmado o profesor García Oro- como se tal Universidade fose o Estudio Xeral da gran provincia eclesiástica compostelana ${ }^{4}$.

${ }^{1}$ DÍAZ y DÍAZ, M., «Problemas de la cultura en los siglos XI-XII. La escuela episcopal de Santiago», Compostellanum, 16 (1971).

${ }^{2}$ RODRÍGUEZ CRUZ, A, «La Universidad de Salamanca en el alba de su historia», en UNIVERSIDAD DE VALLADOLID, Estudios sobre los orígenes de las Universidades españolas. Homenaje de la Universidad de Valladolid a la de Bolonia en su IX Centenario, Valladolid, 1988, pp. 31-42.

${ }^{3}$ BELTRÁN DE HEREDIA, V., Bulario de la Universidad de Salamanca (1219. 1549), Universidad, Salamanca, 1966-67, 3 vols., e Cartulario de la Universidad de Salamanca (1218-1600), Universidad, Salamanca, 1970-73, 6 vols.

${ }^{4}$ GARCÍA ORO, J., «Compostela: Academia de Galicia Medieval»; en UNIVERSIDAD DE VALLADOLID, op. cit., pp. 69-84.

"CUADERNOS DE ESTUDIOS GALLEGOS", Tomo XLVI, Fascículo 111, Santiago 1999. 
Entretanto, neste tempo e durante o século XV na Catedral compostelana mantíñase a Escola de Gramática, a xulgar pola existencia da figura do coengo mestrescola, entre outras dignidades tituladas universitariamente.

En todo caso, desde o ano 1481 e cando menos ata 1486 existen referencias, recollidas por López Ferreiro, relativas ao estudio de gramática e lóxica aberto en Santiago «ao que non desdeñaban asistir os coengos compostelanos $»^{5}$. Deficiente debeu ser o seu funcionamento posterior por canto que o 4 de setembro de 1495, o notario Lope Gómez de Marzoa, que fora rexedor da cidade, obtiña do abade de San Martiño Pinario, Juan de Melgar a cesión dunha parte do mosteiro de Antealtares, para instalar un recen creado Colexio «de Estudiantes pobres» (sic), destinado a Estudio de Gramática (sic), ao que dotou de notables rendas para asegurar o seu funcionamento.

No 1499, con ocasión das reformas monásticas cisnerianas, o Colexio ou Estudio citado, do que coñecemos escasos datos relativos ao seu funcionamento, viuse obrigado a abandonar as instalacións de Antealtares, e todo da entender que asemade paralizou a súa actividade académica.

Sen embargo, pouco despois, mediante unha acción mancomunada do propio Lope Gómez de Marzoa, de Diego de Muros III, Deán en Santiago, e de Diego de Muros II, bispo nas Canarias, refúndase en Santiago «un Estudio de Gramática con un catedrático y un repetidor» (sic), baixo o cuidado de dous visitadores, un do Cabido e outro do Rexemento, coa data de 17 de xullo de 1501. Como garantía académica, «vacante la dicha catedra o repetición o otra lectura que por tiempo oviere, hayan de ser puestos edictos en las Escuelas de Salamanca o de Valladolid, para que se opongan (los candidatos) y sean admitidos por votos de los dichos estudiantes ${ }^{6}$, seguíndose así unha práctica establecida noutros Estudios de Gramática.

${ }^{5}$ LÓPEZ FERrEIRO, A., Galicia en el último tercio del siglo XV, Faro de Vigo, Vigo, 1968, $3^{\text {a }}$ ed., p. 489.

${ }^{6}$ Ibid, pp. 480 e 550 Na p. 488 indica: «A copia non está tomada do orixinal, senón dun exemplar que publicou Neira de Mosquera no tomo de 1852 do Semanario Pintoresco.

A búsqueda de candidatos nas Universidades de Salamanca e Valladolid tamén se practica noutros estudios, cando menos durante o século XVI, como por exemplo ocurriu nos casos de Viveiro e Tui. Desde que Fonseca creou un novo Colexio no ano 1522, houbo o costume de denominar Colexio Vello, ao anterior, sen que tal denominación quixera dicir outra cousa.

"CUADERNOS DE ESTUDIOS GALLEGOS", Tomo XLVI, Fascículo 111, Santiago 1999. 
O Estudio foi situado nunha casa con horta, do Cantón da Rúa Nova, nunha instalación que hoxe se nos antolla humilde, con ensinanza gratuita, «por servicio dos clérigos e dos estudiantes pobres deste Arcebispado e de todo o Reino de Galicia», segundo expresa o mesmo documento fundacional.

A intención de consolidalo e de aumentar a súa importancia debeu guiar a petición por parte dos dous Diego de Muros dunha Bula Papal para o seu recoñecemento, anque descoñecemos o contido explícito da petición. En todo caso, en resposta, o Papa Xullo II asina o 17 de decembro de 1504 a bula «Sane pro parte», segundo a que o Estudio (sic) queda eximido da xurisdicción do Ordinario do lugar -da autoridade civil local-e suxeito á exclusiva dependencia do Deán catedralicio, en canto ás súas cátedras, profesores e estudiantes, concedéndolles o Papa:

(a Diego, Bispo e Diego de Muros) «con plena e libre autoridade, e ao teor do sobredito, licencia e facultade de publicar algúns estatutos e disposicións razonables, sempre que sexan honestos e non contrarios aos sagrados Cánones, polos que se rixan as persoas de aquel Estudio, e todos os publicados se xulgue son procedentes da autoridade apostólica; e queremos que as cátedras erixidas e as que se han de erixir poidan posuír e gozar todos e cada un dos privilexios, inmunidades e exencións de que usan, posúen e gozan as outras Cátedras de Dereito e Artes que se fala nas Universidades de Estudios Xerais e o mesmo os que poidan gozar no futuro» ${ }^{7}$

A citada Bula concedíalle ao Estudio de Santiago e ás Cátedras de Dereito e Artes que no futuro puidera haber, unha parte dos privilexios recoñecidos ás «Universidades de Estudios Xerais» (sic), anque dela non se detrae claramente o recoñecemento do nacemento en Santiago de ningún Estudio Xeral ou Universidade, coas súas correspondentes Facultades e graduacións.

Pouco despois, no 1506, a instancias dunha nova petición, de novo o mesmo Papa extendeu outra bula autorizando a provisión dunha Cátedra de Dereito Canónico no Estudio de Santiago, se ben se descoñece a fortuna real de tal cátedra nos anos posteriores.

${ }^{7}$ Esta Bula está recollida na obra de CABEZA DE LEÓN e FERNÁNDEZ VILLAMIL, Historia de la Universidad de Santiago de Compostela, CSIC/IEGPS., Santiago, 1946, T.I., vol. I., pp. 25-26.

"CUADERNOS DE ESTUdIOS GALLEGOS", Tomo XLVI, Fascículo 111, Santiago 1999. 
Tamén coñecemos que desde este ano, o Bacharel en Artes -había tamén os titulos superiores de Licenciado e Doctor en Artes- Pedro de Victoria, procedente de Salamanca, comeza a exercer como catedrático de Gramática no Estudio Compostelano e ao tempo como administrador das rendas da Institución, ata o ano da súa morte no 1542, sen que, por outra parte, saibamos con certeza o nome dos profesores repetidores.

No 1507 é nomeado arcebispo de Santiago o humanista e renacentista Alonso III de Fonseca, en momentos nos que Diego de Muros III era xa bispo de Mondoñedo, denantes de selo de Oviedo. Os dous estudiaran en Salamanca e Valladolid respectivamente, onde tiñan trabado contactos con destacados profesores humanistas; e, Alonso de Fonseca será en Santiago, como estudiou o profesor García Oro, un auténtico mecenas artístico, promotor dunha cuidada capela musical, sendo ademais un latinista pulcro e culto.

Chegamos a 1517; neste ano, D. Diego de Muros III, bispo de Oviedo funda en Salamanca o Colexio (Maior) de S. Salvador ou de Oviedo, e o mesmo fará no 1521, o arcebispo compostelano Alonso III de Fonseca ao fundar outro Colexio Maior: o de Santiago ou do Arcebispo, autorizado por bula papal de 13 de Outubro de 1525, anque existe constancia documental de se estar construíndo no ano 1519; é mester dicir que ambos os dous Colexios reservan prazas para escolares clérigos procedentes de Galicia ${ }^{8}$.

En 1522, o arcebispo Fonseca decide crear en Santiago un novo Colexio, baixo a advocación de Santiago Alfeo, para estudiantes de Teoloxía, sendo autorizado polo Cabido para utilizar as instalacións do antigo Hospital de Santiago Alfeo, sito na Acibechería, e naquel momento sen función hospitalaria, dada a existencia do Hospital Real, solicitando para o mesmo o recoñecemento papal, anque descoñecemos, polo de agora, o momento exacto da petición e os seus termos.

O que en todo caso sabemos e que xa no 1522 foi nomeado o coengo Joaquín Auñón, versado en Teoloxía, como Rector do novo Colexio. Sabemos tamén que Alonso de Fonseca, nos primeiros meses do 1524, pasa a exercer como Arcebispo mitrado en Toledo, que no 15 de marzo de 1526 firma Clemente VII a bula de recoñecemento do Colexio Santiago Alfeo de Santiago, e que Alonso de Fonseca asina en Alcalá o seu testamento no

${ }^{8}$ ÁLVAREZ VILLAR, J., La Universidad de Salamanca. Arte y tradiciones, Universidad de Salamanca, 1990, pp. 167 e ss.

"CUADERNOS DE ESTUDIOS GALLEGOS", Tomo XLVI, Fascículo 111, Santiago 1999. 
1531, tres anos antes da súa morte no 1534. Será soterrado no Colexio por el creado en Salamanca.

No testamento, fala da intención de facer un «Colexio e Universidade» (sic), quizais a imaxe do Colexio de San Ildefonso, fundado por Cisneros en Alcalá no 1495, como peza central da universidade alcalaína:

«por la experiencia que tovimos de la necesidad que (en el Reyno de Galicia) hay de doctrina, e personas doctas, un colegio e universidad donde los moradores e naturales de dicho Reyno, especialmente de la dicha ciudad y Arzobispado de Santiago, pudiesen estudiar, aprender e ser enseñandos en Gramática y otras facultades, para ser bien instructos en los sacramentos, oficio Divino y otras cosas que convienen»

A bula de 1526, pola súa parte, informa que a nova fundación de Fonseca permitiría a educación de clérigos indoctos, así como sustituir «o vello e pequeno edificio do Colexio vello», que só servía para poucos escolares e lectores (refírese ao fundado no 1501), por un magnífico edificio a construír, unindo a éste o Colexio vello e as súa rendas. A Bula faculta para amplíar este Colexio vello ou mesmo para construír un novo, que foi o que finalmente se fixo. Un Colexio seguindo o modelo de outras cidades con universidade, dando licencia para dictar as convenientes ordenanzas ou Constitucións; ademais:

«eximimos e libramos de toda xurisdición... do ordinario do lugar e dos seus oficiais... e sempre que -e isto será novo e fundamental con respecto á Bula de 1504- algúns dos colexiais do colexio quixesen obter os graos de Bacharel, Licenciado, Doutor, Mestre ou outros graos en Dereito, Teoloxía, Artes, Ciencias e facultades preditas, concedemos, establecemos e ordenamos que observando e resolvendo o que debe ser observado e en dereito resolto, os obteña se alí hai doctores que os examinen e lle confiran graos e do contrario que os obteñan en Salamanca ou noutra calquera Universidade de España» ${ }^{9}$.

\footnotetext{
${ }^{9}$ Transcrición e tradución ao galego a partir da traducción castelán publicada en FRÁGUAS FRÁGUAS, A, O Colexio de Fonseca, Consorcio de Santiago /IEGPS, Universidade de Santiago, 1995, reedición. Estando o texto orixinal da Bula en latín, non se entende a súa transcrición e edición mantida en español na nova edición de 1995.
} 
Adquiría, así o Colexio e Universidade Compostelana a posibilidade de organizar Facultades, como os establecidos Estudios Xerais, e de conceder graos -os diversos diplomas-, anque coa restricción da súa limitación aos colexiais e xa que logo non de modo aberto como nas Universidades plenamente constituídas; restricción que non desapareceu ata a Bula de San Pio V, de 19 de Febreiro de 1567, a pesar das peticións formuladas desde tempo antes polo Claustro compostelano.

É moi escaso o que se coñece sobre a vida académica dos dous colexios compostelanos, durante os primeiros anos que seguen a esta bula de 1526 . No 1531, no seu testamento, dispón Fonseca a construcción dun importante edificio -o actual Colexio Fonseca, constuído no fundamental entre os anos 1532 e 1544- e nomea un Patronato, ao que faculta para que establecese as Constitucións, e sinala a figura do Visitador ordinario designado polo Cabido.

Paralizada a vida académica do Estudio vello coa desaparición do seu Rector e Catedrático Pedro de Victoria, no 1542, o Rector do outro Colexio, o de Fonseca -aínda instalado na Acibechería-, trae de Salamanca como profesor e catedrático de gramática ao humanista tudense Alvaro de Cadaval, no mesmo 1542, e non será ata os anos 1546 e 1547, cando se constata con solidez o funcionamento de senllas cátedras de Cánones e de Sagrada Escritura, atendidas respectivamente polos coengos Doctoral e o Lectoral do Cabido catedralicio. Entretanto, todo parece indicar que aínda non se ocupara o novo edificio colexial fonsecano e diversas incertidumes levan a examinar a algúns membros do Patronato o posible interese de colocar o Colexio-Universidade baixo a dirección dos xesuitas, extremo iste rechazado finalmente. Nestas circunstancias tendo comezado os reis da dinastía dos Austrias a intervir como protectores das universidades hispanas, encárgaselle ao Doctor Cuesta, profesor en Alcalá e Rector do Colexio de San Ildefonso, a reorganización do Colexio-Universidade, no ano 1555, en calidade de Visitador rexio.

Será este quen formula as primeiras Constitucións da Universidade de Santiago, que non serán, sen embargo finalmente aprobadas, como Estatutos filipinos, ata o 1588, e impresas por vez primeira no 1602; a Universidade será colocada baixo Padroado Real; diminúense as atribucións do Colexio Fonseca, mentres se concede primacía ao Rector e ao Claustro da Universidade; indícase a inmediata ocupación do Colexio de Fonseca para Facultade de Teoloxía; destínase o Colexio da Acibechería, que se vai cha- 
mar de San Xerome, para Facultade de Artes, con tres cursos (Súmulas, Lóxica, Filosofía) e para tres cátedras de gramática, non integradas na Facultade de Artes, e postérgase o previsto nacemento da Facultade de Cánones. En total prevíanse doce cátedras: tres para cada un dos estudios facultativos e as tres de gramática, que se irán poñendo en marcha paulatinamente, ata que, finalmente, mediante a Bula de 1567 e o Estatuto de graos, do mesmo ano, asinado por Felipe II, se xeneraliza para todos os alumnos non colexiais a posibilidade de recibir os graos académicos facultativos, extendidos logo aos estudios de Medicina e de Dereito Civil, iniciados en Santiago a mediados do século XVII.

\section{¿CANDO DATAR A ORIXE E A FUNDACIÓN DA UNIVER- SIDADE DE SANTIAGO? OS HISTORIADORES GALEGOS ANTE A CUESTIÓN}

Este longo proceso no que aparecen as datas de 1495, 1501, 1504, $1522,1526,1555$ e 1567, a falta de rotundidade na expresión que amosan os documentos primeiros, a tardía aparición documental do concepto «universidade» (1526) e outros factores aludidos, fixeron que, en particular, na historiografía galega se teñan rexistrado dúbidas sobre a datación da Universidade de Santiago, ou, noutros casos, seguridades asentadas sobre presupostos incertos.

Neira de Mosquera, nas súas Monografías escritas a mediados do século XIX consideraba que en Santiago non existira Universidade ata a Bula de Clemente VII, de $1526^{10}$. Pola súa parte, Pérez Bustamante e González García-Paz, no 1934, consideran o mesmo argumento ${ }^{11}$, anque recoñecen antecendentes a partir de 1495 . En termos similares se expresaron Salvador Cabeza e Fernández Villamil na súa clásica historia da

${ }^{10}$ NEIRA DE MOSQUERA, Monografías de Santiago y diversos temas compostelanos (1844-1852), Bibliófilos Gallegos, Santiago, 1950, pp. 267-275.

" PÉREZ BUSTAMANTE, GONZÁLEZ GARCÍA-PAZ, La Universidad de Santiago (El pasado y el presente), Ed. facsimilar, O Castro, Sada, 1995. Distinguen entre a etapa do Estudio Vello a partir do 1495 -«a partir de aquí se inicia la Universidad», din na p. 9- e a creación da Universidade con Fonseca.

"CUADERNOS DE ESTUDIOS GALLEGOS", Tomo XLVI, Fascículo 111, Santiago 1999. 
Universidade Compostelana ${ }^{12}$, distinguindo a fase de antecedentes, os fundamentos definitivos da fundación con Fonseca e a organización definitiva a cargo de Dr. Cuesta.

Esta centralidade da data de 1526 quedou rota nas formulacións de García Oro, publicadas por primeira vez no 1976 no seu libro Diego de Muros III y la Cultura Gallega ${ }^{13}$, ao denominar a creación de 1501 (o Estudio de Gramática) como «Estudio General de Compostela, un estudio general de gramática», extremo reafirmado coa seguinte tese: «Coas disposicións desta Bula -refírese á de 1504-atopaba a súa definitiva fisonomía o Estudio Xeral de Galicia, que xa estaba frisando o decenio da súa vida ${ }^{14}$. Utilizaba o profesor García Oro os termos «Estudio Xeral» e «estudio xeral de gramática», que non aparecen como tais nos documentos de 1501 e 1504.

A renglón seguido, na historia institucional da Universidade, editada no ano $1980^{15}$, o mesmo profesor, que elabora o capítulo das orixes, mantén a mesma tese exposta anteriormente. O profesor Riobó nun breve e ben construído traballo sobre o nacemento da Universidade de Santiago no contexto renancentista ${ }^{16}$, deixa entender que a posteriori da bula de 1504 , anque a institución «non pasaba da categoría de Colexio, nos seus resultados era xa practicamente unha Universidade».

Asemade, nos finais dos pasados anos oitenta Angel Portabales e Laura Varela no seu relato da historia da Universidade, publicado na Gran Enciclopedia Gallega ${ }^{17}$ xa lle chaman «Estudio General Compostelano» ao

${ }^{12}$ CABEZA DE LEÓN, S., FERNÁNDEZ VILLAMIL, E., Historia de la Universidad de Santiago de Compostela, 3 Tt., Santiago, CSIC/IEGPS, 1945, con Prólogo de P. Pedret Casado.

${ }^{13}$ GARCÍA ORO, S., Diego de Muros III y la cultura gallega del siglo XV, Galaxia, Vigo, 1976.

${ }^{14}$ Ibid, pp. 84 e 88

${ }^{15}$ DÍAZ y DÍAZ, M.C. (Coord.), La Universidad de Santiago, Servicio de Publicacións da Universidade, 1980. GARCÍA ORO, «Compostela: Academia de la Galicia Medieval». Co peso da súa autoridade académica histórica acreditada senta un parcial novo modo de ver as cousas, de modo que a étapa de antecedentes quedaba restrinxida á dos anos 1495-1504. Neste último xa funciona un «estudio (general) abierto a la ciudad entera». Esta apertura aos non clérigos non autoriza a denominar ao estudio como «general».

${ }^{16}$ RIOBÓ GONZÁLEZ, M., «Santiago de Compostela, una Universidad del Renacimiento (sus vinculaciones con la Orden de la Merced»), Estudios (Revista Mercedaria), 153 (1986) 5-16.

${ }^{17}$ PORTABALES VÁZQUEZ, A., VARELA, I., «Universidad», Gran Enciclopedia Gallega, T. XXIX.

"CUADERNOS DE ESTUDIOS GALLEGOS", Tomo XLVI, Fascículo 111, Santiago 1999. 
Estudio de 1495, se ben indican que «a súa constitución definitiva data de 1504, por bula papal que permite a súa futura ramificación en cátedras e facultades» (sic), sendo que o concepto de Facultade non aparece na bula de 1504, como tampouco e concepto de Estudio Xeral. Aínda así afirman: «Alfonso de Fonseca III conclúe o Estudio Xeral». Pegerto Saavedra, pola súa parte, volve ás posicións de Pérez Bustamante, salientando, en todo caso que: «Admitese que a orixe da Universidade está no Estudio Vello de $1495 »^{18}$.

De novo, García Oro en 1988 ten ocasión de escribir con respecto á creación de 1501: «O que agora se programaba era un Estudio Xeral» (sic), anque anotando que se ben «na Acta Fundacional se lle chama Estudio de Gramática, na documentación específica aparece designado con frecuencia como Estudio Xeral»... «A data definitiva universitaria de Santiago e a de 15 de marzo de 1525» (sic), que na nova cronoloxía gregoriana hai que entender como $1526^{19}$.

Os profesores Manuel Lucas Álvarez e M. J. Justo Martín na edición diplomática das primeiras fontes documentais da nosa universidade, de $1991^{20}$, din que o que se funda no 1501 é un Estudio Xeral (sic). Naqueles momentos Barreiro Fernández ao escribir sobre o asunto ${ }^{21}$, chámalle «Estudio Xeral de Gramática» á creación de 1501, anque afirma que non é aínda Universidade: «o que temos ata este momento en Santiago é un Estudio, un colexio no que se ensina algo que é previo ó ensino universitario» (sic).

Posteriormente, o profesor García Oro ao realizar o «Estudio Introductorio» á edición das Actas de Visita do Licenciado Portocarrero á Universidade de Santiago de 1577 afirma que no 1501 queda deseñado un Estudio Xeral de Gramática en Compostela, indicando que «o ano 1542 é

\footnotetext{
${ }^{18}$ SAAVEDRA, P., Historia de Galicia II, Planeta, Barcelona, 1990, p. 82.

${ }^{19}$ GARCÍA ORO, J., en Estudios sobre los origenes, op. cit., pp. 83 e 84.

${ }^{20}$ LUCAS ÁLVAREZ, M., JUSTO MARTÍN, Fontes documentais da Universidade de Santiago de Compostela (1237-1537). Edición diplomática, Consello da Cultura Galega, Santiago, 1991.

${ }^{21}$ BARREIRO FERNÁNDEZ, X.R., Historia de Galicia T. IV, Hercules de Ediciones, A Coruña, 1991, pp. 137, 141-142.
}

"CUADERNOS DE ESTUDIOS GALLEGOS", Tomo XLVI, Fascículo 111, Santiago 1999. 
o fito que sinala a división entre as duas etapas, a do Estudio Xeral e a do Colexio e Universidade de Fonseca» ${ }^{22}$.

Chegamos así ao gran Catálogo das Exposicións conmemorativas do V Centenario ${ }^{23}$. Neste documento, Ana Gay ${ }^{24}$ indica que Lopo Gómez, Diego de Muros II e Diego de Muros III «no 1501 fundan o Estudio Xeral» (sic), ao que lle concede o Papa no 1504 «gozar dos mesmos privilexios cas Universidades e os Estudios Xerais» (sic). A tese do Estudio Xeral fundado no 1501 é tamén sostida por $\mathrm{M}^{\mathrm{a}} \mathrm{J}$. Justo Martín $^{25}$ e por Pilar Rodríguez Suárez ${ }^{26}$, anque tamén indica: «mentras o Estudio Xeral comezaba as súas reducidas actividades académicas, Alonso de Fonseca proxectaba crear en Santiago un colexio universitario que dotase ó Reino de Galicia dun centro de estudios superior» dándose logo a entender que o Estudio Xeral de 1501 non o era.

Esta mesma investigadora, á que lle debemos notables estudios sobre o desenvolvemento primeiro da Universidade de Santiago, terá ocasión de escribir noutro lugar:

«O Estudio Xeral de Compostela, malia ter os privilexios que tiñan o resto da Universidades -o que é dubidoso ante a incapacidade para graduar-, non se pode considerar como tal, porque polo seu tipo de docencia (gramática) e pola súa estructura, quedaba ben lonxe de ser unha universidade como se concibía no século XVI», debendose agardar a Alonso de Fonseca ${ }^{27}$.

Aínda noutro lugar, a mesma investigadora segue chamándolle Estudio Xeral de Gramática ao centro creado no 1501, ademais de indicar que

${ }^{22}$ GARCÍA ORO, «Estudio introductorio» a Miguel ROMANÍ e P. RODRÍGUEZ SUÁREZ, (Eds.) Actas da Visita do Licenciado D. Pedro Portocarrero, Gobernador de Galicia (1577), Servicio de Publicacións da Universidade de Santiago, 1992, pp. XIXXXI e XXIV.

${ }^{23}$ UNIVERSIDADE DE SANTIAGO, Cinco séculos de historia universitaria. Gallaecia Fulget (1495-1995). Catálogo das Exposicións, Servicio de Publicacións da Universidade, Santiago, 1995.

${ }^{24}$ Ibid, p. 54.

${ }^{25}$ Ibid, p. 54

${ }^{26} \mathrm{Ibid}, \mathrm{p} .118$.

${ }^{27}$ M. P. RODRÍGUEZ SUÁREZ, «A Universidade de Santiago nos séculos XVI e XVII», Revista Galega do Ensino, 11 (1996) p. 25.

"CUADERNOS DE ESTUDIOS GALLEGOS", Tomo XLVI, Fascículo 111, Santiago 1999. 
Alonso de Fonseca aspiraba a crear un colexio universitario; «tendo en conta que xa existe en Santiago un Estudio Xeral, afirma (Fonseca) que este non responde xa a súa función» $(\mathrm{sic})^{28}$.

Por fin, cauto nos apelativos, o profesor Díaz y Díaz, despois de afirmar: «A Universidade de Santiago reclama con toda a razón as súas orixes naquela decisión de Lopo Gómez (de 1495)», plantea como debate fonsecano a fórmula pola que inclinarse: a de Estudio Xeral ou a dunha Universidade Colexio, inclinándose por esta última, logo do que solicita Fonseca unha nova bula; «baseándose en que o Estudio instituido mediante bula de Xullo II non cumpría a súa función, e por iso había que o incorporar e fundilo co centro proxectado, de maneira que se puidese converter no mencianado Colexio e Universidade, que chegase a colaciona -los graos todos de Artes, Teoloxía e Cánones» $(\mathrm{sic})^{29}$.

Neste percorrido, podemos apreciar a presencia de acepcións varias nos documentos e nos escritos dos historiadores citados; mesmo se rexistra unha contribución nosa seguidora das posicións maoiritariamente expre$\operatorname{sadas}^{30}$ : Estudio, Estudio Xeral, Centro de Gramática, Estudio Xeral de Gramática, Colexio, Colexio-Universidade, Universidade; acepcións usadas a miudo sen a precisa cautela, podendo inducir a erro.

\section{A HISTORIA DAS UNIVERSIDADES E OS SEUS CONCEPTOS}

A través dun proceso non uniforme, en diversos lugares de Europa entre finais do Século XII e inicios do Século XIII naceron agremiacións de estudiantes e profesores que procuraban un superior rigor de estudio e formación que o ofrecido ata o momento pola xeneralidade das escolas catedralicias, a miudo centradas no estudio do Trivio: gramática, retórica, dialéctica e unha reducida formación relixiosa / teolóxica. Son os casos de

${ }^{28}$ M. P. RODRÍGUEZ SUÁREZ, La Universidad de Santiago en el Siglo XVI. Los libros de Claustro. 1566-1600, Barrié de la Maza/Galicia Histórica, A Coruña, 1996, pp. 16 e 20.

${ }^{29}$ DÍAZ y DÍAZ, M. C. «Onte e hoxe fronte ó mañá na Universidade de Santiago». Revista Galega do Ensino, 11 (1996), pp. 216 e 218.

${ }^{30}$ COSTA RICO, A., «Universidade, cultura e língua na Galicia do antigo réxime», Grial, 114 (1992) pp. 212-224. Eu tamén falo do Estudio Xeral de Compostela en 1504, seguindo o xa escrito por outros historiadores. Sen embargo, desde o momento do coñecemento, a través dos medios de comunicación, da intención de realizar no 1995 a conmemoración do $\mathrm{V}^{\circ}$ Centenario tiven ocasión de expresar as miñas reservas.

"CUADERNOS DE ESTUDIOS GALLEGOS", Tomo XLVI, Fascículo 111, Santiago 1999. 
Montpellier, de Salerno, de Bolonia, de Oxford e de París... dando paso á consolidación de Estudios e de corporacións xuradas de profesores ou de profesores e estudiantes ou só de estudiantes, que encontraron relativamente pronto o amparo papal, real ou imperial, mediante Bulas ou Cartas de recoñecemento da súa personalidade xurídica, que lles conferían un estatuto singular, protector dos intereses dos que participaban en tales corporacións de estudio, baixo modelos gremiais, de tal modo que se podían formar «universitates», é dicir gremios entre os profesores e entre os estudiantes.

Sobre a base da súa personalidade xurídica poden establecer a súa xurisdición interna, ordenar a súa estructura e a súa organización para o estudio, o que ten lugar a través dos seus Estatutos, como o da «universitas magistrorum» de Paris de 1215, contando sempre cos dictados das Bulas e das Cartas de recoñecemento. En canto á organización dos seus estudios, cómpre salientar que se estructuran mediante o concepto de Facultades, delineándose desde cedo as Facultades de Artes - que chegará a converterse en auténtica Facultade de Filosofía-, a de Teoloxía e a de Cánones, pronto seguidas pola de Medicina, previamente presente a través da «Física» estudiada en Artes, de non ser casos específicos como os de Montpellier e Salerno, inicialmente xa constituídos como Escolas de Medicina. A elas se ía engadir tamén a Facultade de Leis, como espacio de estudio do Dereito Romano e do Dereito Real.

Os Estudios nacen pois de diverso modo, podendo constituirse neles unha ou máis «universitates», obteñen recoñecemento e personalidade xurídica, aproban os seus Estatutos ou Constitucións, cun número variable de Facultades, desde unha ata as catro habituais, e reciben cada vez máis a denominación de Estudios Xerais (Studium Generale), especialmente durante o século XV.

Reciben esta denominación sobre todo cando son varias as Facultades que os integran, cando os que alí estudian non están necesariamente condicionados polas Constitucións de outros gremios ou corporacións e cando se lle recoñece validez pública aos diplomas acadados neles. Diferenciándose, así, dos «Estudios particulares», organizados sustancialmente polos bieitos, cistercienses, dominicos e franciscanos -co tempo tamén por parte doutras ordes relixiosas-. Estas Ordes, que organizan Estudios para os seus membros, nos seus documentos, tamén clasificarán os seus Estudios como «Xerais» ou «provinciais», anque aos ollos externos non terán máis que a consideración de Estudios particulares da orde respectiva. 
Nos Estudios Xerais, os graos académicos -Bacharelato, Licencia, Doutorado ou Mestría- coroan os diversos estudios facultativos. A través deles recoñécese a «licentia ou facultas ubique docendi» con caracter universal na cristiandade, no caso dos Estudios Xerais de Bolonia, Paris e Salamanca e máis tardíamente no caso de Oxford, é dicir, un recoñecemento «universal» dos titulos expedidos. Case sempre, a «licentia» é «respectu regni», é dicir, ten unha validez limitada ao espacio político no que se asenta un determinado Estudio Xeral; e non se lles recoñece estas cualificacións a outro tipo de Estudios.

Sendo a formación impartida dispensada en lingua latina, ante a precariedade das estructuras formativas existentes fora dos Estudios Xerais, e sendo o seu dominio unha condición para a realización de estudios facultativos, xunto á creación autónoma de Escolas e Estudios de Gramática, os propios Estudios Xerais estableceron cátedras de gramática nas súas Facultades de Artes -sendo esta Facultade considerada como «menor» e propedéutica aos Estudios das Facultades «superiores»-, chegando a separarse en senso estricto dos cursos de Artes, por ser unha preparación previa.

O que se entendía por un Estudio Xeral xa se formulaba na lexislación real impulsada por Alfonso X, a través de Las Partidas (1256-1264), coa experiencia previa e avanzada da Universidade de Salamanca, fundada polo seu avó, confirmada mediante Real Cédula de 1243 do seu pai Fernando III, polas súas mesmas disposicións de 1244 e pola bula de 1255 Interea quae placite:

Ley I.-Qué cosa es Estudio e cuántas maneras son de él, e por cuyo mandato deben ser fechos. Estudio es ayuntamiento de maestros e escolares, que es fecho en algún lugar con voluntad e entendimiento de aprender los saberes. E son dos maneras de él. La una es a que dicen Estudio general, en que hay maestros de las artes, así como de gramática e de la lógica e de retórica e de aritmética e de geometría e de astrología; e otrosí en que haya maestros de decretos e señores de leyes. E este Estudio debe ser establecido por el mandado del papa o del emperador o del rey.

La segunda manera es a que dicen Estudio particular, que quiere tanto decir como cuando algún maestro muestra apartadamente en alguna villa a pocos escolares. E tal como este pueden mandar facer prelado o concejo de algún lugar. 
Ley III.- Cuántos maestros deben ser en el Estudio general e a qué plazos deben ser pagados sus salarios. Para ser el Estudio general complido, cuantas son las esciencias, tantos deben ser los maestros que las muestren, así que cada una de ellas haya un maestro a lo menos. Pero si para todas las esciencias no pudiese haber maestro, abonda que haya de gramática, e de lógica, e de retórica, e de leyes e de decretos. E los salarios de los maestros deben ser establecidos por el rey, señalando ciertamente cuánto haya cada uno, según la esciencia que mostrare o según que fuera sabidor de ella. E aquel salario que hubieren de haber cada uno de ellos, débenselo pagar en tres veces. La una parte les deben dar luego que comenzaren el estudio. La segunda, por la Pascua de Resurrección. La tercera, por la fiesta de San Juan Bautista.

A historiografía universitaria e os autores de xeral recoñecemento reafirman o ata aquí expresado.

$\mathrm{H}$. Rashdall, o autor de The Universities of Europe ${ }^{31}$ manifesta que á fin da Idade Media o concepto de Studium Generale fai referencia á existencia dunha organización escolar recoñecida co «ius ubique docendi» («respectu regni») para os que se graduan nela. Pola súa parte, D’lrsay asenta o concepto de Studium Generale sobre o recoñecemento papal e real da autonomía escolar e da xurisdición eclesiástica, fronte aos Estudios locais e particulares ${ }^{32}$.

Pola súa parte, Jacques Verger manifesta:

«Un Studium generale era unha institución de educación superior fundada sobre ou, en calquer caso, confirmada no seu status por unha autoridade de caracter universal, na que os seus membros gozaban dun certo número de dereitos, igualmente universais, que trascendían todas as divisións locais» ${ }^{33}$.

${ }^{31}$ RASHDALL, H., The Universities of Europe in the Middle Ages, Clarendon Press, 1987, 3 vols (orix. de 1895), Vid. Cap. $1^{\circ}$.

${ }^{32} \mathrm{D}$ IRSAY, St. Historie des Universités françaises et étrangères des origines a nos jours, T.I.: Moyen Age et Renaissance, E. Auguste Picard, Paris, 1933, p. 142.

${ }^{33}$ J. VERGER, «Esquemas», in HILDE DE RIDDER-SYMOENS (Ed.), Vol. I. Las Universidades en la Edad Media, Servicio Editorial de la Universidad del País Vasco, 1994 (orix.: 1992), pp. 39, 41.

"CUADERNOS DE ESTUDIOS GALLEGOS", Tomo XLVI, Fascículo 111, Santiago 1999. 
O que non impedía que os alumnos de escolas que non eran universidades puideran en ocasións obter un ou outro privilexio dos que estaban restinxidos normalmente aos membros dos Studia Generalia.

O mesmo Verger matiza: «para os homes da Idade Media, so podía haber un Studium Generale onde se ensinaba unha disciplina «Superior» (Teoloxía, Dereito, Medicina: indicación nosa), é dicir, perfecta e completa, tanto en termos da «autenticidade» do coñecemento que contiña, como en termos do seu obxectivo social» ${ }^{34}$.

Co paso do tempo, en particular, durante o seculo XV o concepto «universidade», que tradicionalmente definía a un gremio, comenzou a utilizarse indistintamente co de studium generale. Aparecerán tamén diversas innovacións nas estructuras universitarias, indica Verger, volvéndose complexa a tipoloxía e a terminoloxía destas institucións no contexto europeo, dado que na época moderna mutiplícanse arredor das universidades strictu sensu, establecementos máis ou menos desprovistos do dereito de colación de grados, aínda que sen embargo aseguran ensinanzas do tipo, cando menos parcialmente, «superior ${ }^{35}$; en todo caso permanece $o$ concepto de universidade como «comunidade autónoma de mestres e de estudiantes reunidos para asegurar a un nivel superior a ensinanza dun certo número de disciplinas» ${ }^{36}$.

Con respecto á complexidade tipolóxica aludida cómpre anotar que desde finais do seculo XV e ao longo do século XVI, se rexistrou en España un considerable crecemento das fundacións de estudios superiores, seguindo ben, o modelo tradicional de Studium generale, ou os novos de colexio-universidade e de convento-universidade, neste caso maioritariamente a cargo dos dominicos. Colexios e conventos-universidade, onde se imparte un ensino universitario/superior, no seo dunha reducida comunidade colexial de estudiantes escollidos e becados, gobernados e suxeitos a estatutos fundacionais; nestes casos concentráronse nos estudios de gramática, artes, teoloxía e cánones ${ }^{37}$ e tiveron con frecuencia dificultade de

\footnotetext{
${ }^{34}$ Ibid, p. 48.

${ }^{35}$ CHARLE, Ch. e VERGER, J., Histoire des universités, PUF, Paris, 1994, pp. 37-38.

${ }^{36} \mathrm{Ibid}, \mathrm{p} .3$.

${ }^{37}$ RODRÍGUEZ SAN PEDRO-BEZARES, Luis E., La Universidad Salmantina. del Barroco, 1598-1625. I. El modelo barroco. Gobierno y Hacienda. Ed. Universidad de Salamanca, 1986, pp. 196 e ss.
}

"CUADERNOS DE ESTUDIOS GALLEGOS", Tomo XLVI, Fascículo 111, Santiago 1999. 
recoñecemento dos seus estudios. Nalgúns casos pasaron de ser ColexiosUniversidade a Universidade, tal como ocurriu en Alcalá ou en Santiago (aquí desde o 1555).

\section{FUNDACIÓNS UNIVERSITARIAS HISPÁNICAS ${ }^{38}$}

Por volta de 1208-9 fúndase o primeiro Estudio Xeral en Palencia, no reino de Castela, desaparecido poucas décadas despois. Serán fundados -segundo a data de recoñecemento papal ou real- outros Estudios Xerais en Salamanca $(1218,1243)$, Sevilla (1254, refundado no 1502), Lleida (1300), Valladolid (1346), Huesca (1354, restaurado no 1464), Girona (1446, restaurado no 1579), Barcelona (1450), Zaragoza (1474), Palma (1483) con dificultade de recoñecemento de títulos ata o 1673), Sigüenza (1489), e Valencia (1500). Ata fins do século XVI outros Centros se crearán, seguindo diversos modelos:

\begin{tabular}{lll}
\hline Estudio Xeral & Colexio - Universidade & Convento - Universidade \\
\hline 1526 - Granada & 1521 - Toledo & 1534 - Sahagún (desde 1560 en Irache) \\
$(1555$ - Santiago) & 1526 - Santiago & 1547 - Gandía \\
& 1540 - Oñate & 1550 - Almagro \\
& 1442 - Baeza & 1569 - Orihuela \\
& 1549 - Osuna & 1576 - Ávila \\
& 1555 - Burgo de Osuna & 1587 - El Escorial \\
\hline
\end{tabular}

\section{PRECISIÓNS COMPOSTELANAS. A UNIVERSIDADE DE SANTIAGO E A HISTORIA EUROPEA DAS UNIVERSIDADES}

Cos anteriores antecedentes, cremos estar en condicións de concluír que:

- O que se funda en Santiago tanto no 1495 como no 1501 é un Estudio de Gramática, que non pode ser definido en ningún momento como

\footnotetext{
${ }^{38} \mathrm{Ibid}$, pp. 196 e ss.

${ }^{39}$ RASHDALL, H., The Universities of Europe..., Op. cit.

"CUADERNOS DE ESTUdiOS GALLEGOS", Tomo XLVI, Fascículo 111, Santiago 1999.
} 
Studium generale (Estudio Xeral), porque o estudio da gramática non constitúe un ensino «superior». E mesmo propedéutico para a Facultade menor de Artes.

- A Bula de 1504 recoñece tal Estudio e concedelle unha parte dos privilexios de que gozan as Universidades de Estudios Xerais. Implicitamente recoñecese que o Estudio de Santiago non é unha Universidade. Anque fala de recoñecer privilexios para as cátedras que no futuro puidera haber, non contemplaba a organización de facultades, nin a concesión de graos ou «licencia ubique docendi»; o que nalgunha medida explica as peticións formuladas por Fonseca, momentos antes de 1526.

- A posibilidade de organización de Facultades, de concesión de graos, anque de modo limitado, e de fundación da universidade en Santiago só queda claramente confirmada pola bula de 1526 .

- A fundación universitaria aparece baixo a formula de ColexioUniversidade e só, logo das Constitucións do Dr. Cuesta de 1555, estaremos ante a posibilidade dunha Universidade de Estudios Xerais, anque a plena concesión de graos non quedará establecida ata o ano de 1567.

- Establecida a fundación da Universidade de Santiago e o seu recoñecemento papal a través de bula de 1526, é mester entender que as súas orixes e antecedentes inmediatos se achan no Estudio de Gramática de 1495 e nos pasos dados de seguindo.

- A data de recoñecemento Papal, Imperial ou Real é a que se toma en consideración como criterio normativo na historiografía universitaria para establecer a cronoloxía da fundación das Universidades, e non a data dos antecedentes respectivos, coidando que en case todos os casos foi un proceso o que ten conducido á respectiva fundación e recoñecendo que non sería doado establecer a escala internacional tal cronoloxía procesal, así como o significado e o valor de todos e cada un dos dados relativos a antecedentes.

Por iso mesmo, os mapas e taboas cronolóxicas de xeralizado uso académico parten de ordinario do primeiro documento oficial creador do Estudio Xeral / Universidade. Así, non ten aparecido en tales rexistros a universidade de Santiago de Compostela, coa data do 1495 ou mesmo a de 1504, agás nos mapas insertos no Catálogo das Exposicións do V Centenario Compostelano.

"CUADERNOS DE ESTUDIOS GALLEGOS", Tomo XLVI, Fascículo 111, Santiago 1999. 
¿De que mapas e taboas estamos a falar?. En primeiro lugar dos de Rashdall ${ }^{39}$, de xeral recoñecemento europeo, de ordinario seguido, con algunhas rectificacións a tantos anos de distancia da primeira edición, por outros investigadores e mesmo polo propio Catálogo compostelano (páx. 109), excepto na datación das Universidades da Península Ibérica ${ }^{40}$; neste último caso, as datacións son azarosas ás veces ou inducen a erro ou son incompletas e non digamos o Mapa que alí aparece das Universidades españolas ata principios do seculo XVII (pax. 111), onde as confusións son a norma.

Tomamos tamén en consideración o mapa de A. Piltz, que ten a virtude de ofrecer ademais entre parentese, en bastantes casos, a data na que por vez primeira se menciona o concepto «universidade ${ }^{41}$. Seguimos, asemade, o de Franco Cardini publicado no $1992^{42}$, e, por último, os publicados na historia oficial e institucional das universidades en Europa ${ }^{43}$, historia ésta amparada pola Conferencia Permanente de Rectores, Presidentes e Vicechanceleres das Universidades de Europa (CRE), tamén editada no 1992, actualizando os dados do anterior Historical Compendium of European Universities do ano 1984.

Hai nas obras anteriores unha xeral coincidencia na datación da fundación de cada Universidade, como consecuencia da aplicación dun similar criterio normativo, que foi sen embargo desconsiderado ou deficientemente aplicado polo conxunto de historiografía universitaria galega.

${ }^{40}$ UNIVERSIDADE DE SANTIAGO, Cinco Séculos de vida universitaria, Santiago, 1995, Op. cit. Ademais das pp. 109 e 111, para as que non consta fonte nin autoría, tamén, cando menos na p. 188, e coa sinatura de $\mathrm{M}^{\mathrm{a}} \mathrm{J}$. Gutierrez Tosar se produce unha defectuosa explicación dos contidos das bulas de 1504 e de 1526.

${ }^{41}$ PILTZ, A., The World of Medieval Learning, Blackwell, Oxford, 1981.

${ }^{42}$ CARDINI, F., et alii, Universidades de Europa. Raices culturales del Viejo Mundo, Anaya, Madrid, 1992.

${ }^{43}$ J. VERGER, «Esquemas», en HILDE DE RIDDER SYMOENS, op. cit., pp. 7072 e $76-82$

"CUADERNOS DE ESTUDIOS GALLEGOS", Tomo XLVI, Fascículo 111, Santiago 1999. 


\section{A OPORTUNIDADE DA CONMEMORACIÓN DO V CENTE- NARIO DURANTE O CURSO 1995-96}

A comunidade universitaria compostelana, representativamente a través da Xunta de Goberno, avalou tal oportunidade na súa sesión do 22 de decembro de 1992, o que gozou como sabemos do refrendo institucional, oficial e social posterior.

Fíxoo sobre un texto documental que se inicia do seguinte modo:

«En 1495 iniciouse o proceso de creación dos estudios universitarios en Santiago de Compostela coa instalación en San Paio de Antealtares do Estudio General (sic) promovido por Lope Gómez de Marzoa...».

En termos similares o expresaron os medios de comunicación en extenso número de ocasións. E creo que se trata, despois do argumentado, dunha información historicamente defectuosa.

En todo caso, pode ser apropiado referirse ao que tivo ocasión de escribir o ex-Rector da Universidade de Santiago D. Carlos Pajares:

«No ano 1988 consultarase con varios historiadores e expertos sobre a idoneidade de considerar 1995 como a data conmemorativa. A resposta foi unánime: 1495 pode considerarse como a orixe fundacional.

El mesmo indica:

«Non hai unha norma xeral aceptada para establece-la data fundacional dunha Universidade. O autor destas liñas non é historiador e polo tanto as afirmacións relacionadas coa Historia deberán ser confirmadas por especialistas do campo. Dito isto, si parece que a norma xeral que se adopta é elixir como data a conmemorar a máis antiga das datas posibles, sen entrar noutras consideracións $»^{45}$.

${ }^{44}$ CRE, Historical Compendium of European Universities, Xenebra, 1984.

${ }^{45}$ PAJARES VALES «Medio milenio», Revista Galega do Ensino, 11 (1996) p. 240. 


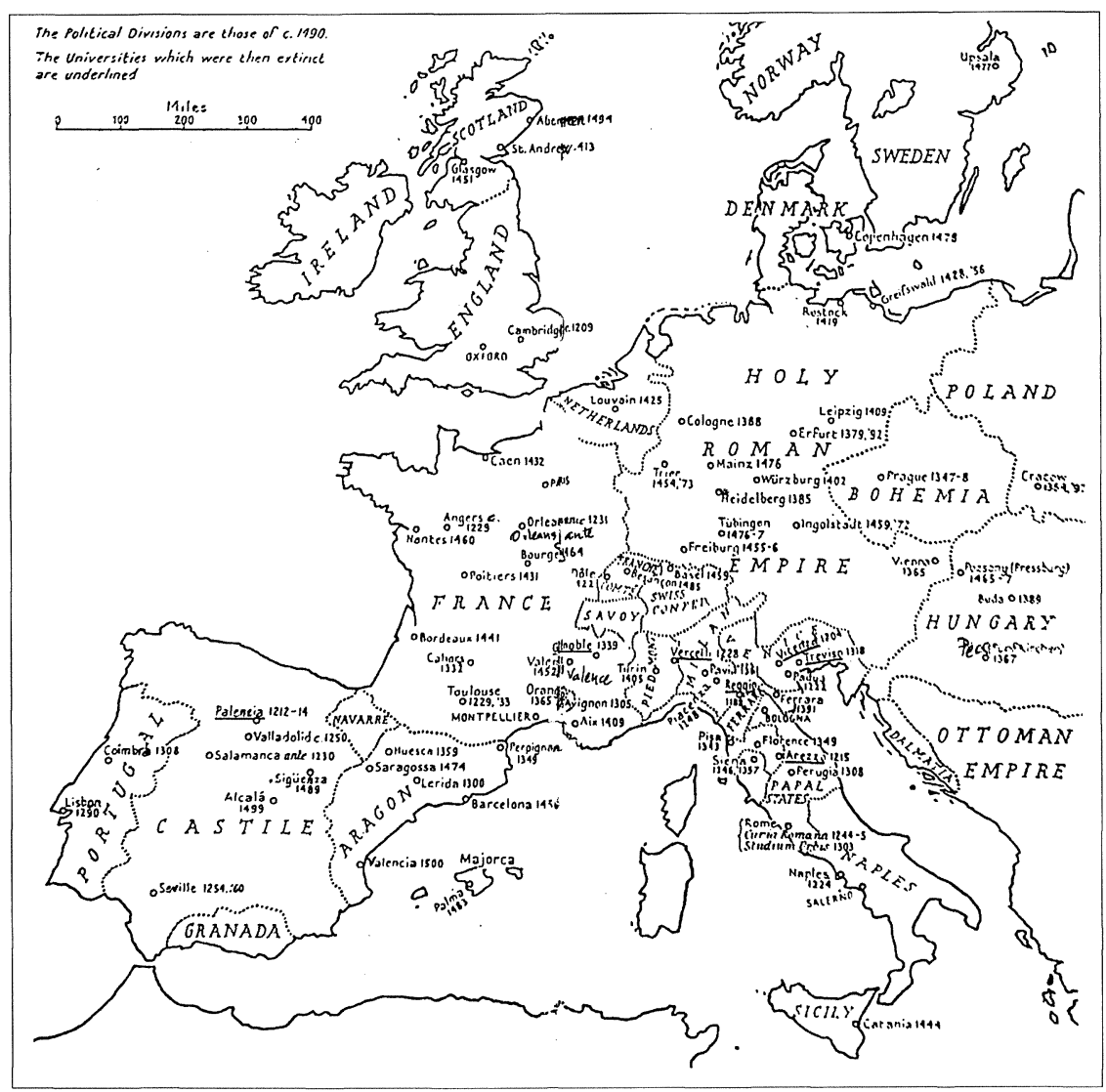

Fig. 1.- Medieval University Towns

Tomado de H. Rashdall: The Universities of Europe in the middle Ages at the Clarendon Press, Oxford, 1987 ( $1^{\mathbf{a}}$ ed.: 1936). 


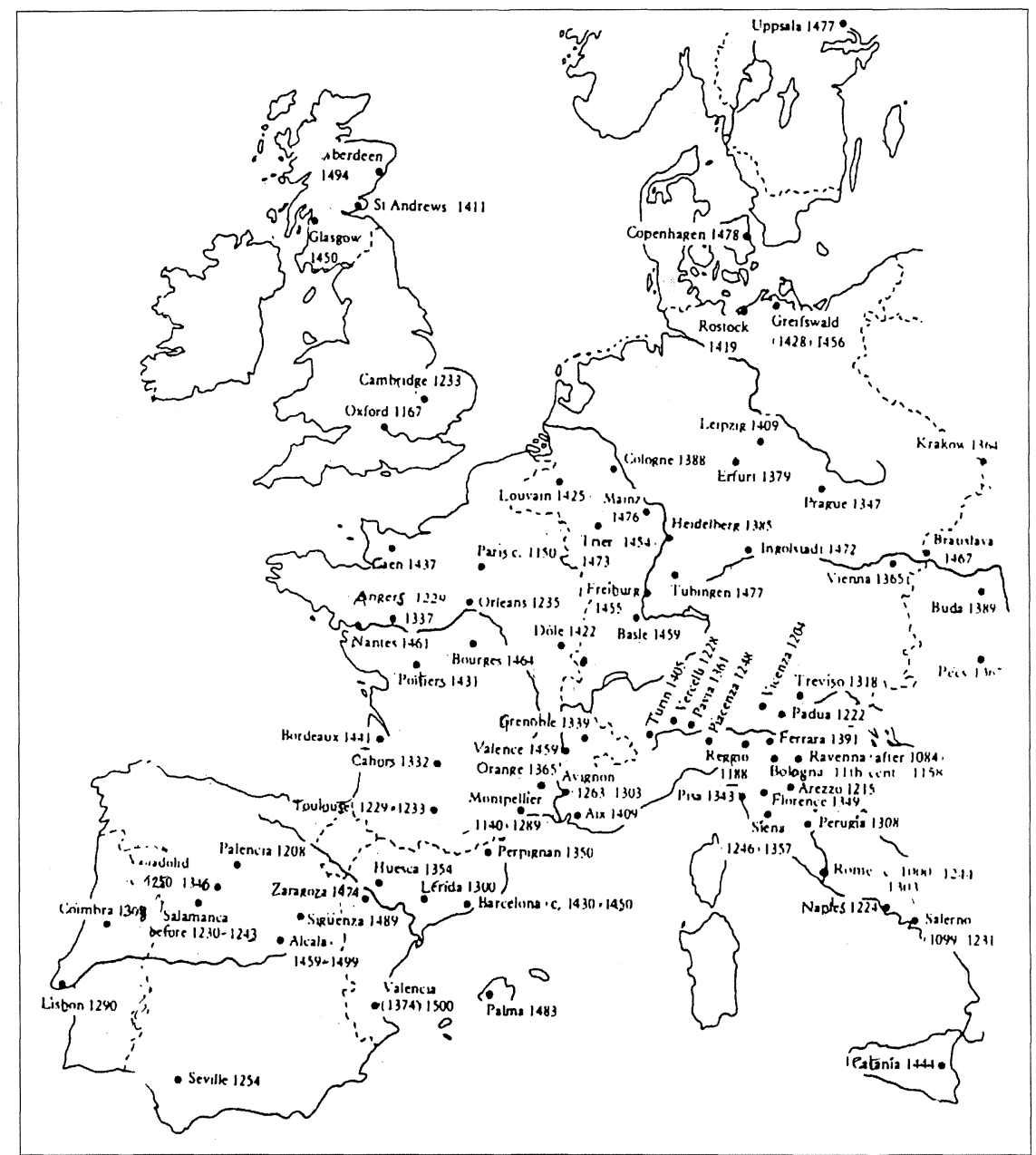

Fig. 2.- Las Universidades europeas hasta 1500.

Las fechas indican el año en el que fue otorgada la carta de fundación.

Las fechas entre paréntesis indican la primera vez que se menciona a la Universidad en una fuente escrita.

Tomado de A. Piltz: The World of Medieval Learning. Oxford, Basil Blackwell, 1981. 


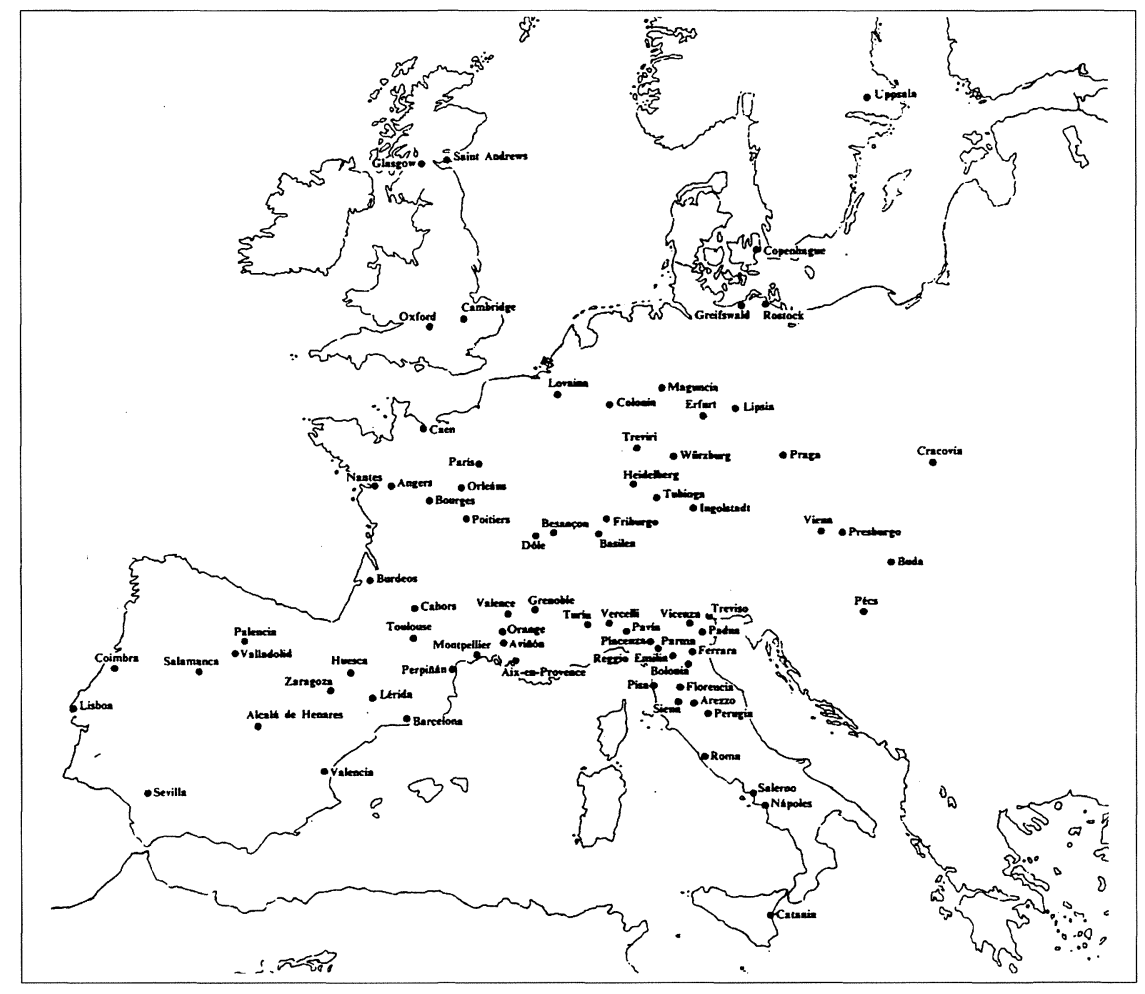

Fig. 3.- Universidades de Europa (Ano 1500)

Tomado de F. Carnini et alii, Universidades de Europa Raíces Culturales del Viejo Mundo, Anaya, Madrid, 1991. 


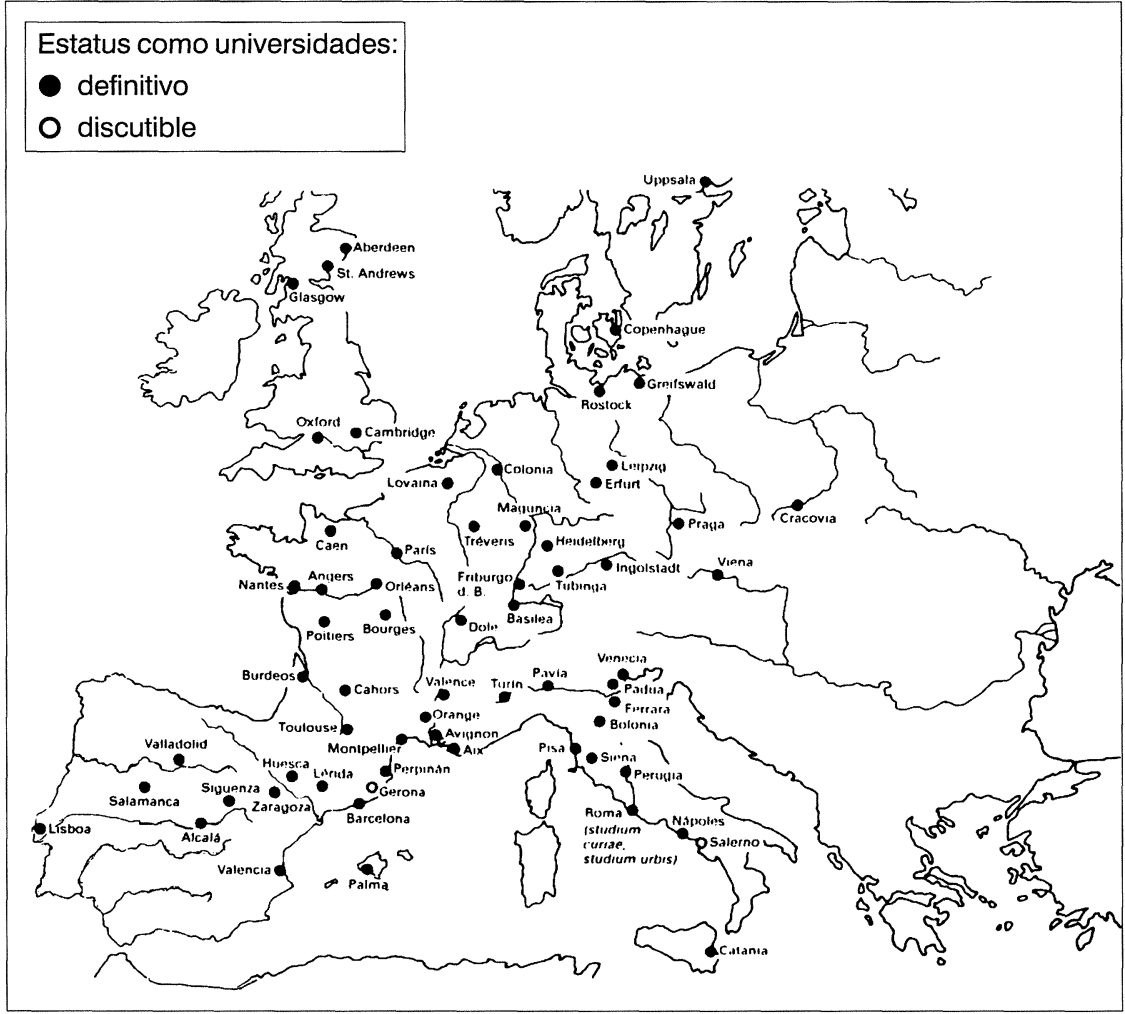

Fig. 4.- Universidades activas en 1500.

Tomado de Hilde de Ridder-Symoens (Ed.), Las Universidades en la Edad Media, Vol. 1, Universidad del País Vasco, 1994, p. 82 


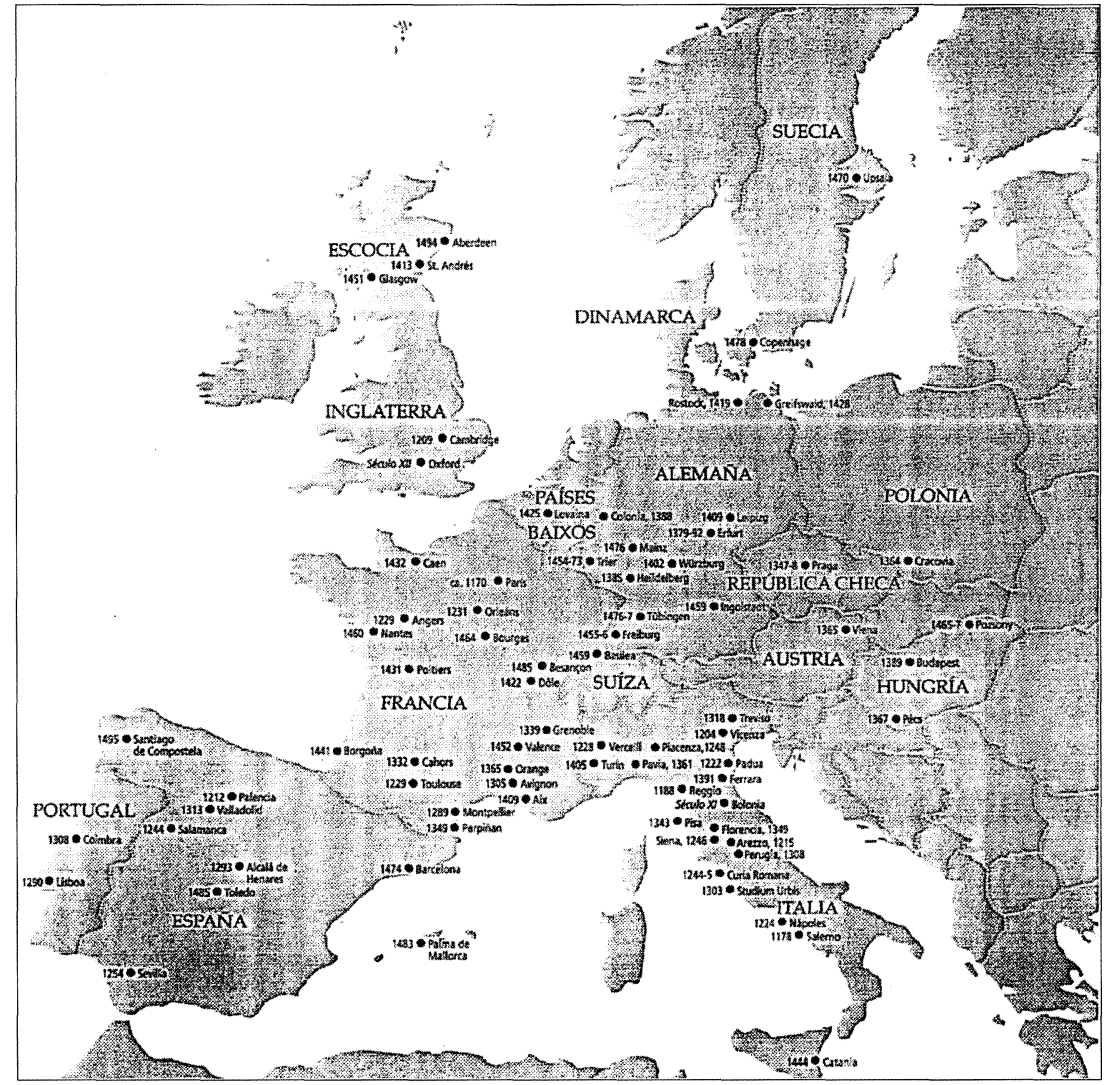

Fig. 5.- Primeiras universidades europeas entre os séculos XII e XV. (Altas). Tomado da Universidade de Santiago, Cinco séculos de historia universitaria. Gallaecia Fulget (1495-1995). Catálogo das exposicións, Santiago, 1995. 


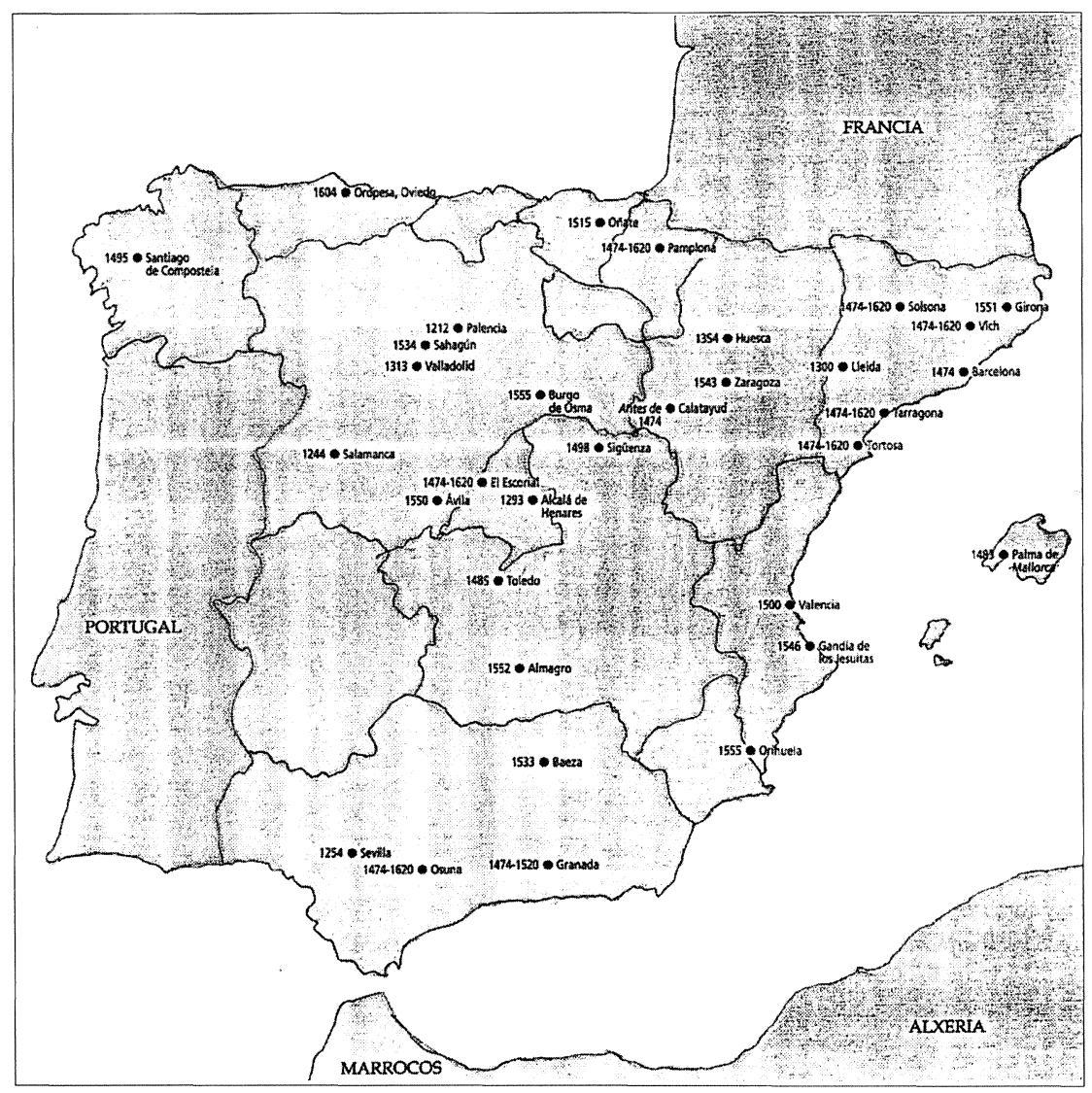

Fig. 6.- As universidades españolas ata principios do século XVII Tomado da Universidade de Santiago, Cinco séculos de historia universitaria. Gallaecia Fulget (1495-1995). Catálogo das exposicións, Santiago, 1995. 